\title{
Exploration and Practice on the Curriculum Design Project Guidance for the Course of Engineering Design and Drawing
}

\author{
Chaoyong Guo \\ Department of Vehicles and Electrical Engineering \\ Ordnance Engineering College. \\ Shijiazhuang, China \\ Guochy1963@163.com
}

\author{
Haiying Huang \\ Department of Vehicles and Electrical Engineering \\ Ordnance Engineering College. \\ Shijiazhuang, China \\ Haiying72@sina.com
}

\begin{abstract}
In combination with the practice of curriculum design on engineering design and drawing course for undergraduate students, the paper summarizes and analyzes the issues relative to the design project selection, the design proposal, the design guidance, the engineering drawing generating, and the thesis writing during the curriculum design project. According to these specific issues, the paper puts forward some more effective approaches and strategies to guide the curriculum design project and improve the teaching quality of the course.
\end{abstract}

Keywords-component; engineering design and drawing; curriculum design; curriculum design project

\section{INTRODUCTION}

Engineering design and drawing is a course for engineering college of non mechanical majors. It is the first kind of engineering course after students enter school, and it undertakes the task of teaching students engineering design knowledge and cultivating the preliminary engineering design and expression ability. Graduation is the last practical teaching link of the course. Not only it is a preliminary test of learning achievement of the course, but also an important comprehensive training of engineering design and expression skills to the students. At the same time, the quality of curriculum design thesis is the important basis to measure the level of curriculum teaching and student's expression ability. Therefore, earnestly doing a good job guidance curriculum design work, and constantly improving students' paper quality and comprehensive practical skills are the bounden duty of teachers[1][2] .

Generally, it requires a combination of practical application to the course of engineering design drafting. First of all, students are required to complete a specific job, such as designing principles of simple mechanical system, improving the design of mechanical structure, engineering shape and assembly design and so on. On this basis, draw the relevant engineering drawings and finish the thesis written work. While the time for undergraduate curriculum design is very limited, from the opening to the respondent, there is only 1 month's time, and in the middle period there have other courses, along with the fact that most of the students is first in contact with the engineering problems, lacking of practical engineering experience and skills, and some seemingly simple often taking a long time to solve, which cause some students' curriculum design can not achieve the desired goal, the strengthening of the role of teachers' guidance and supervision is imperative, brooking no delay. Following the author and combining with the experience of instructing my college students' curriculum design, starting from an instructor's angle, we has carried on some thinking and discussion practice on how to be more effectively in guiding the curriculum design and improving the pattern and quality of papers[3].

\section{THE CHOICE OF TOPIC SHOULD BE TARGETED, CLEAR AND OPEN}

For students learning this course, most of whom are in the initial contact with engineering actual work, they hardly have the ability to design topic choice[4]. Therefore, in the choice of project we adopted the "walking on two legs", this is to combine restricting the selection with self-selection. First teachers put forward some subject name and requirements, then the students choose one to complete; second, students put forward design task, and then the guiding teacher estimate as curriculum design project. In either case, the guidance teachers should grasp is that the selected course design task must be targeted to a certain extent. On one hand, it is aiming at the main knowledge of curriculum learning to make subject, and cannot be separated from the course of learning and teaching objectives; on the other hand, it is aiming at the ability for students to choose project, small, easy to make results, but also can exercise the student subject, not "high, big, fine, sharp", or the students in the limited time only can cope with the problem in hurry, it is difficult to achieve the desired teaching objectives. The requirements of the course design task also need to be clear. When guiding teachers give students curriculum design task, they should make clear that the subject needs what basic knowledge, need what work, to do how far and form last of complete etc. To abandon those unrealistic creativity requirement and big empty task, teachers will be able to grasp the workload of the whole project, and become more conducive to arrange and control the progress of project guiding. For students, they can also have a clear target direction, and more easily and rapidly get into the subject to carry out the work, so as to complete the curriculum design and achieve the purpose 
of the training of curriculum design. Curriculum design project should also be open, one is an open plan, to fully mobilize the enthusiasm of the students' innovation and exert their subjective initiative; the other one is an open work, under the premise of ensuring the basic training effect, work should leave certain elastic space in order to make the students who have difficulties can complete the task on schedule.

\section{THROUGH THE OPENING REPORT TO PROMOTE CURRICULUM DESIGN}

The opening report generally describes the following aspects: the meaning of the subject; the present situation; specific problems to solve and the methods, scheme, technical route and schedule arrangement etc. The opening report is planned after students receive the task of curriculum design, and require students to conduct adequate research and careful writing. After students complete the opening report, guiding teachers need to review the opening report, listen to students' report, and the research contents, technical routes as well as methods will be questioned, then put forward constructive suggestions. The opening report has the vital significance for teachers to understand students' ability and promote the study to go on according to plan.

\section{A. The opening report to promote the students' development}

Writing opening report is the first try for a student to carefully consider how to develop a written report subject. The strengthened guidance and review to opening report can promote students to project into in-depth research, thinking and understanding, and therefore students can carry out the next step of work more reasonably. At the same time, through the guidance of teachers' questions or suggestions, students can find the problems and the insufficiency, proposes more reasonable plan and technical route and schedule, and to avoid the later detours, reduce waste the design time.

\section{B. The opening report to promote teachers' guidance work}

The process of the opening report can also be a process of communication and understanding between teachers and students. The course design task is just guiding teachers' plan and requirement. Though communication on the opening report, teachers may discover student's knowledge advantage or defect timely, then according to the ability level of the students teach students in accordance with their aptitude, and then adjust the aim and guiding arrangement. It can promote the completement of the subject.

\section{The opening report on the promotion of drawing and writing paper.}

Before the opening report, students don't have experiences on research papers' writing, thus opening report is not only the prelude but also the first rehearsal and training on the students. Through the guiding teachers' review, teachers clearly told the students problems of the opening report writing and content and improving methods, throwing students not only into indepth understanding of the subject, but also exercising their writing ability. And the basis of topic selection and review in opening report can both be quoted directly in the curriculum design thesis and content framework. Report can also be course design paper reference, the so-called " Grinding a chopper will not hold up the work of cutting firewood”, good opening report can effectively reduce the burden of future writing papers.

\section{WITH DRAWINGS AND PAPER CATALOG FOR GRASPER, GUARANTEE THE QUALITY OF DESIGN}

When the students finish the work task of curriculum design, the only thing left to do is to draw engineering drawings and writing thesis. According to the author's experience of guidance, students' completing task does not mean that they can draw the high quality patterns and write thesis well, but also the pattern of mistakes are just satisfactory. The main manifestations in this aspect are: pattern: kinematic diagram drawing are not standardized, projection relation is not correct, lack of the necessary annotation, not comply with the national standard drawing regulations, simple to projection as engineering drawings; patchwork plagiarism is obvious, the organized chaos and so on.

How to avoid the above problems in advance? Through practice, the author found that most drawing problems can be solved by "signature each trial ". This problem can be avoided by determining the contents and the outline of the paper in the writing of a thesis. The author's approach is, when students finish the task after work, first ask students to list the contents and outline of the thesis, and then carefully check for modifications, find out the problem, and students work together to determine the contents and outline of the thesis; finally let the students write the first draft according to this directory and outline. Through this process, students completed the draft paper, and then generally there is no big problem in the content and the structure, then guidance teachers can do further check for modifications, delete the contents of no great importance in the paper, and do the core work to strengthen the outstanding thesis, emphasizing the research results or conclusions etc.. Through these practices, finally teachers can guide students to better complete the curriculum design project in the limited time.

\section{CONCLUDING REMARKS}

In this paper, combining with the practice of guiding the course design of engineering design drawing, we carry on a discussion on some typical problems in the process of guiding, and obtained some certain reference valuable to guidance method and strategy. These methods and strategies as long as the arrangement, would not take guidance teachers extra time and energy, but can effectively promote the successful completion of the course and improve the design quality. Of course, the student's own subjective initiative is one of the important factors that affect the curriculum design, but for every guiding teacher, with a serious and responsible attitude, as long as they constantly sum up and thinking, improve their guidance method and enhance guidance level, they will continue to improving the overall quality of the guidance of curriculum design.

\section{REFERENCES}

[1] Yuan Baolun and Han Songlai. "Discussion and Reflection on the guidance method for engineering undergraduate graduation design". Journal of Higher Education Research. 2011,vol.34(3):pp69-71. (in Chinese) 
[2] Zhang Juping, Kang Yebin and $\mathrm{Li}$ Xiuzhen, "Analysis on the improvement of graduation design (Thesis) quality strategy”.China modern educational equipment, 2009, vol.73(3): pp54-57. (in Chinese)

[3] Lin Chuntao and Ning Hongru. "Current situation and improvement measures of undergraduate graduation design (Thesis) to investigate”. China Light Industry Education, 2008(3): PP47-48. (in Chinese)
[4] Li Hongyan, Su Xiaosi and Bian Jianmin. "Teaching exploration for undergraduate graduation design (Thesis)”. Jilin Education. 2008(3):pp8-9. (in Chinese) 